* Corresponding author Phone: +421556023545 E-mail address:jan.slota@tuke.sk (Ján Slota, doc. Ing. PhD.)

Article information Article history: AMS-Volume15-No.4-00134-11 Received 12 April 2011 Accepted 12 May 201

\section{Optical Measuring of 3D Deformation in Sheet Metal Forming}

\author{
Emil Spišák, Ján Slota*, Miroslav Tomáš, Emil Evin, Jana Majerníková \\ Department of Technologies and Materials, Faculty of Mechanical Engineering, Mäsiarska 74, 04201 Košice, Slovak Republic
}

\section{BIOGRAPHICAL NOTES}

Emil Spišák, prof. Ing. CSc. (born 1955) is professor of Department of Technologies and Materials, Faculty of Mechanical Engineering, Technical University of Košice. He is head of the Department of Technologies and Materials and Vice-Rector for Development and Construction of the University. He served as Vice-Dean for 4 years and ViceRector for 8 years. He works in the area of evaluating of material properties, material failures, analysis and quantification of production factors influence in production of thin steel sheet stamping parts, modelling and simulation of technological processes, mainly forming processes. He is national secretary and a member of International Deep-Drawing Research Group. He is author of 5 monographs and more than 200 publications in journals and conference proceedings at Slovakia and abroad. His published works were cited 115 times. He has been worked on 60 grant projects, research tasks and 47 projects solved for industry.

Ján Slota, doc. Ing. PhD. (born 1974) is associated professor of Department of Technologies and Materials, Faculty of Mechanical Engineering, Technical University of Košice. He is graduated on Faculty of Mechanical Engineering, TU in Košice, where he received also scientific degree $\mathrm{PhD}$ and where he habilitated at the field of mechanical engineering processes and materials. From 2004, he has been head of section of Computer Aided of Production Engineering on the Department. His research works are mainly focused on the area of computer simulations in deep-drawing processes. He is a member of International Deep-Drawing Research Group. He is author of three university textbooks and more than 70 publications in journals and conference proceedings at Slovakia and abroad. He has been worked on several grant projects, research tasks and many projects solved for industry.

Miroslav Tomáš, Ing. PhD. (born 1973) is currently assistant professor at the Technical University of Košice, Faculty of Mechanical Engineering, Department of Technologies and Materials. He graduated in Forming Technology (1996), obtained the PhD. in the field of deep drawing of complicated rotary symmetrical cups at the Technical University of Košice in 2001. In his research work he focuses on metal forming technologies, research of stress-strain state at forming processes, evaluation of material and process formability of sheets, forming dies design using CAD software, simulation software implementation in stamped parts design process and research of material models used in simulation. He is the author of 48 scientific works at journals in Slovakia and abroad, 66 contributions on national and international scientific conferences and 2 textbooks. He has been worked on 16 research or grant projects and on 28 projects for industry. Emil Evin, prof. Ing. CSc. (born 1956) is a professor in the scientific area of Engineering Technologies and Materials, Faculty of Mechanical Engineering at the Technical University in Kosice. He graduated the Faculty of Mechanical Engineering, Technical University of Kosice (1980). He was inaugurated as a professor in 2010 with his work "Verification of numerical simulation of formability of high strength steel sheets" in the 
field of Mechanical Engineering Technologies and Materials. Prof. Evin pass through the study and lecture stays in Technische Hochshule Zwickau, Technical University in Kielce, Technical Universities in Maribor and Ljubljana; and Technical University in Chemnitz. Long term, his scientific and research activities are oriented to the field of technological prediction of formability of steel sheets with higher strength properties, testing of material properties of steel sheets, simulation of stamping processes, the evaluation of the technicaleconomic level of production and engineering products. Prof. Evin was the principal investigator of 3 VEGA projects, co-partner of several national and international scientific research projects and dozens of projects for practice. His activities in the Technical University in Košice: Deputy of Head of Department, member of the Common Branch Committee "Mechanical Engineering Technologies and Materials", a member of the Faculty Commission "Mechanical Engineering Technologies and Materials" Examination Commission for a doctoral level of study at the MTF STU Trnava, expert and judge (reviewer) of the Slovak National Accreditation Service. He is co-author of one monograph, 5 university textbooks, over 180 original scientific papers published in domestic and foreign journals and proceedings.

Janka Majerníková, Ing., PhD. (born 1966) is an assistant professor at the Department of Technology and Materials, Faculty of Mechanical Engineering, Technical University of Košice. She received scientific degree PhD. in 2008 in the field of limit strains of tinplates by different stress-strain states. She is an author of more than 50 publications in journals and conference proceeding in Slovakia and abroad. She has been worked on several grant projects.

\section{KEY WORDS}

Forming, Sheet Metal, Strain Analysis, Optical Measurement

\section{ABSTRACT}

During recent years, optical measuring technologies in sheet metal forming and tooling have been used more and more in the industry. Main applications are the digitizing of metal sheet parts and tools, forming analysis of metal sheets as well as the determination of material properties. Good interfaces to conventional CAD/CAM and numerical simulation systems made such optical measuring systems a part of complex process chains. These process chains mainly focus on optimizing the development of products and production processes and on improving the product quality. Using optical systems considerably decreases the development time for products and production while improving the quality. This paper presents the use of 3D surface geometry data of formed sheet metal part for determining limit strains. Furthermore, the measured strain and thickness reduction distributions is evaluated.

\section{Introduction}

Stamping processes, especially deep drawing process, belongs to the most complicated processes in shape changing operations of metal forming. Complexity of the deep-drawing process is conditioned by the fact there are different stress-strain states acting from process start till the end in the same location of the workpiece. Mentioned result to different values of pressing's wall thickness as an effect of plastic deformations distribution during deep-drawing process. [1]

Theory of forming or plasticity theory serves as a basis for metalforming processes. It is a phenomenological theory based on analytically or mathematically described behaviour of material continuum during plastic deformation. Beside other tasks, theory of forming solves analysis of deformations during forming processes in order to determine the appropriate shape and dimensions of the initial workpiece, or shape and dimensions of workpieces for each stage at multi-operational forming processes. Theory of forming also defines limit conditions of plastic deformations, when material plasticity is overdrawn and failure of formed part occurs. There are used followed methods for forming process analysis $[2,3,4]$ :

1.Analytic - method of plane sections, energetic method (work equilibrium), slip lines method, upper bound method, finite element method, etc. - these methods are based on exact equations describing a particular metalforming process and their solutions are usually difficult, so there are made a number of simplifying assumptions to their reduction.

2.Experimental-analytic - deformation resistance method, hardness measurement method, visualisation of plastic flow method, deformation net method, layered models method and microscopic 
methods, etc. - these methods are based on real process examination and evaluation using similarity law. They are commonly used to improving analytical methods.

Analysis of forming processes by finite element method (FEM) is used at present due to powerful computers and software improvement. In the FEM, the workpiece is divided into elements that are assumed to be interconnected at discrete number of nodal points located on their boundaries. Then, at each element, a set of equations are usually assigned with constant parameters which are identified to the nodal point velocities. These equations in each region are combined to form an admissible velocity field which satisfied the necessary requirements except the volume constancy requirement. The later is enforced by the variational principle, which also allows the calculation of the mean stress, strain, forces, deformation work, etc. [3]

Method of deformation network (or grid) is experimental method used to analysis of deformation at stamping processes of steel sheets. Distribution of plastic deformation is researched by this method based on change of network (grid) put on sheet surface. Different types of network elements are used - square, rhomb, circle or their combinations. These network elements are put on steel sheet surface by drawing, printing, etching, photographically and they are not allowed to influence the way that the steel sheet is deformed and to make notch effect also. [2,4]

Evaluation of deformation network is labor-intensive and subjective, because it is very difficult to determine the place of localised deformation and cracked network (fractured workpiece) is also difficult to evaluate. The significant progress has brought the development of systems for the transformation of the physical model or product in the computer model, using an optical measurement and digitization. These optical systems allow contactless way to capture the geometry of the part but also to evaluate workpiece deformation and its motion over time. For these purposes irregular network (grid) is used. Next, optical measuring system ARGUS will be discussed.

\section{Measuring of 3D deformations by non-contact optical method}

The optimization of sheet metal forming processes, considering the right material choice and tool optimization, is a decisive factor for competitiveness, particularly in the automotive industry.

The optical 3D forming analysis system ARGUS supports such optimization processes with precise results of the forming distribution of components. The results from the ARGUS system provide fullfield information about $[5,6]$ :

$3 D$ coordinates of the component's surface

Form change (major and minor strain)

Thickness reduction

Forming Limit Diagram (FLD)

ARGUS is designed to measure the strain and thickness reduction in sheet metal caused by stamping, to detect hot spots in the validation process of new and reworked stamping tools and to measure the formability of sheet metal in stamping applications.

It is a non-contact optical 3D deformation measuring system, which can make analyzes, calculates and documents deformations of sheet metal parts, for example. It provides the 3D coordinates of the component's surface as well as the distribution of major and minor strain on the surface and the material thickness reduction. In the Forming Limit Diagram, the measured deformations are compared to the material characteristics. ARGUS supports optimization processes in sheet metal forming by means of $[5,6,7]$ :

- Fast detection of critical deformation areas

- Solving complex forming problems

- Verification of numerical simulations

- Verification of FE models

- Creation of Forming Limit Curves, FLC

- Comparison of measured deformations to the material characteristics by means of a Forming Limit Diagram.

The optical forming analysis provides for precise and fast measurement of small and large components using a high scanning density. ARGUS operates independently of the material. It can analyze components made from flat blanks, tubes or other components manufactured by an internal high pressure forming process (IHPF, Hydroforming).

\section{The principle of the method}

For a measurement using the measuring system ARGUS, circular dots are applied to the original sheet metal with a regular spacing of typically 1 $\mathrm{mm}$ to $5 \mathrm{~mm}$ prior to the forming process [5]. For this purpose, mainly structures are used that were created by electrochemical etching, laser 
etching or printing. In our case it was the electrochemical etching (Fig. 1). These dots follow the deformation of the part during the forming process and are maintained even in case of large relative movement between the sheet metal and the tool. The centre of these dots is the reference for determining the coordinates and for the following deformation analysis.

ARGUS compares the 3D positions of measuring points in a deformed and in an undeformed state.

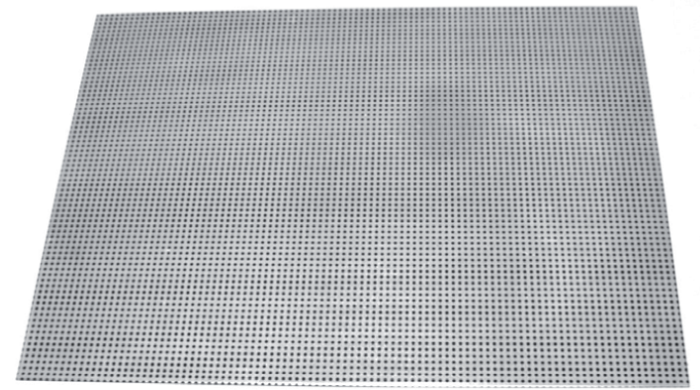

Fig. 1: Regular dot pattern on a flat metal sheet.

Then, the shaped component is recorded with a digital CCD camera (with a resolution of $2352 \times 1728$ pixels or $4288 \times 2848$ pixels) from various views (Fig. 2).

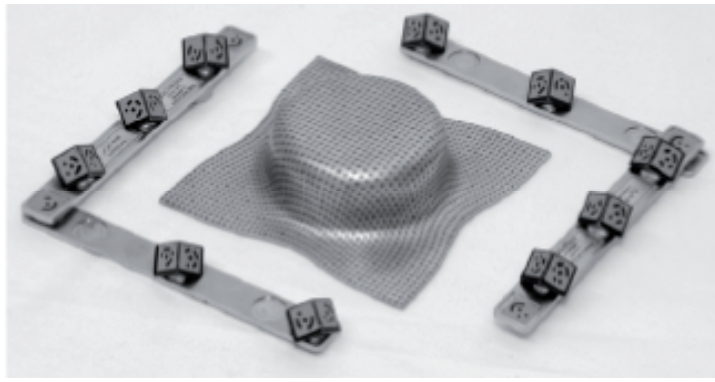

Fig. 2: Example for a shaped metal sheet after the forming process.

Prior to the deformation, a regular point pattern is applied to the surface of the measuring object.

For measuring objects which undergo high friction during the forming process, the measuring points are applied, for example, with the help of electrolytic methods. After the forming process of the measuring object, a camera (online or standalone operation) records the measuring points in several different images with different views.

Photogrammetric algorithms use these images to determine the 3D coordinates of the dots on the sheet metal. Thus, the entire surface of the shaped sheet metal is described according to the density of the etched structure.

For the automatic spatial orientation of the individual images or views, coded points are position close to or on the measuring object.

The basic idea of photogrammetry is to look at points (coded and uncoded) from different directions and to calculate the 3D coordinates of these points from the images or point rays thus obtained. The points visible in an image have a fixed relation to each other. Therefore, by means of images made from other angles of view, it is possible to calculate the camera location using this point relation [6].

First, the resulting point cloud consists of distorted points that are not assigned (Fig. 3).

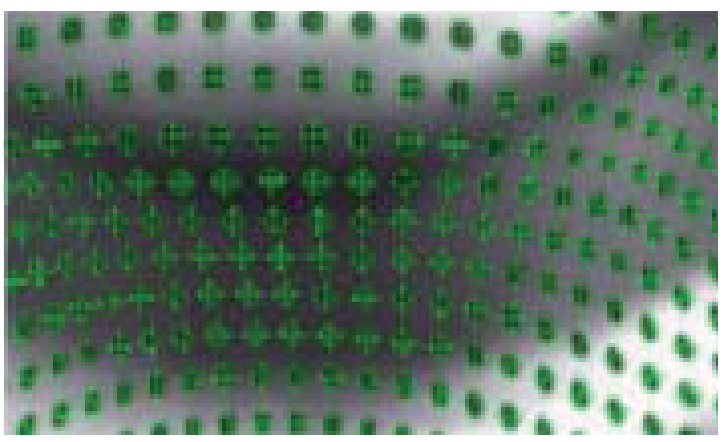

Fig. 3: 2D image with idenfied measuring points.

Now, the system automatically creates a mesh assigning the points to their correct neighbors (Fig. 4).

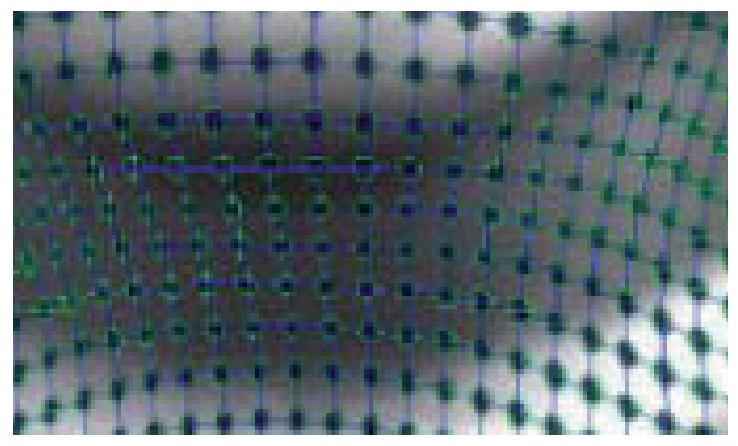

Fig. 4: Created mesh after point calculation.

Then, in this mesh, for example each $2 \times 2$ point field is compared to the original geometry and the corresponding surface strain tensor in space is determined (Fig. 5). 


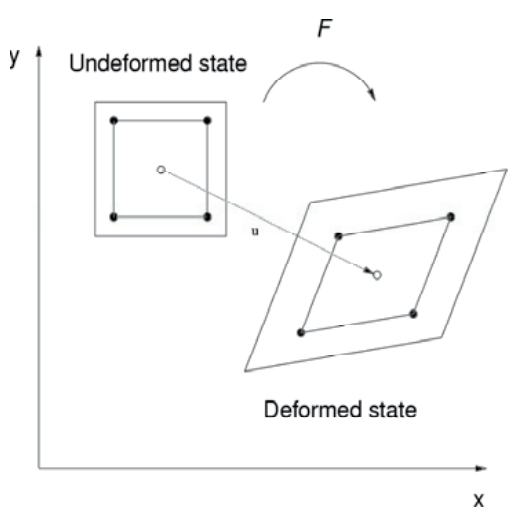

Fig. 5: Calculation of the surface strain tensor.

During the acquisition of an image set it is the goal to record points from multiple different directions that show the largest possible angles to each other.

It is the task of the ARGUS software to precisely find ellipses (a perspective view of point surfaces) in all images of the image set and their 3D orientation. The ARGUS software interprets the images and generates $3 \mathrm{D}$ measuring data.

In order to compute the strain, the undeformed state is compared to the deformed state. In a standard measuring project, the undeformed state, the strain reference, is not captured optically but results from the theoretical point distance defined in the project parameters. As a default, the system presumes an exactly regular initial pattern which is on one plane and for which the point distance is known. This is called the "virtual reference stage" and is marked with Stage 0 in italic letters in the software. All strain values refer to the adjusted computation parameter Point distance.

The ARGUS software is also capable of analyzing several static deformation states (stages) within one project where each deformation stage can be set as strain reference any time. This procedure may be used, for example, for the deformation analysis of tubes [5].

To allow for a full-field view of the strain, the software changes to the so-called grid mode. This means that based on the center points of the measuring points a grid surface is created. Each grid line intersection point represents a 3D measuring point. The full-field color representation of the strain results (Fig. 6) from the 3D positions of these grid line intersection points.

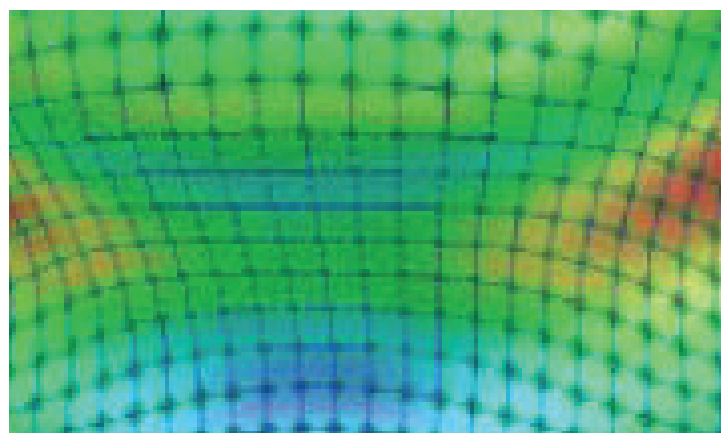

Fig. 6: 2D image with idenfied measuring points in evaluation mode (overlay representaion).

\section{Experimental material}

Steel sheet of the new conception used in automotive industry was evaluated during experimental works. Evaluated microalloyed steel sheet (H220PD) was fully hot-dip galvanized with amount of zinc of $100 \mathrm{~g} / \mathrm{m} 2$. Evaluation of material drawability of experimental materials was realized by tensile test (STN EN ISO 6892-1:2010-01), test of planar anisotropy, test of normal anisotropy ratio (ISO 10113:2006) and test of strain hardening exponent (ISO 10275:2007). Significant directions of $0^{\circ}, 45^{\circ}$ and $90^{\circ}$ against direction of rolling were tested during testing of drawability parameters. Tensile specimen according to STN EN 10002-1, $\mathrm{LO}=80 \mathrm{~mm}$ was used for all mentioned tests. The tests were realized on the tensile machine TiraTEST 2300 with recording of the process. Interval of strain hardening exponent evaluation was within the range of uniform deformation of $5-20 \%$ for tested sheet.

Table 1: Chemical composition of experimental material.

\begin{tabular}{|l|l|l|l|l|l|}
\hline $\mathbf{C}$ & $\mathbf{M n}$ & $\mathbf{P}$ & $\mathbf{S}$ & $\mathbf{T i}$ & $\mathbf{S i}$ \\
\hline 0.004 & 0.415 & 0.042 & 0.004 & 0.037 & 0.1 \\
\hline Al & $\mathbf{C r}$ & $\mathbf{C u}$ & $\mathbf{N b}$ & Mo & \\
\hline 0.035 & 0.031 & 0.011 & 0.026 & 0.005 & \\
\hline
\end{tabular}

Chemical composition of experimental material is shown in Tab. 1. Values of mechanical properties, degree of their planar anisotropy, coefficient of normal anisotropy and strain hardening exponent are shown in Tab. 2.

Table 2: Mechanical properties of experimental material.

\begin{tabular}{|l|l|l|l|l|l|}
\hline $\mathbf{R}_{\mathbf{p 0 . 2}}$ [MPa] & $\mathbf{R}_{\mathbf{m}}$ [MPa] & $\mathbf{A}_{\mathbf{8 0}}[\mathbf{\%}]$ & $\mathbf{r}_{\mathbf{m}}$ & $\mathbf{\Delta r}$ & $\mathbf{n}_{\mathbf{m}}$ \\
\hline 227 & 378 & 36 & 1,64 & 0,28 & 0,23 \\
\hline
\end{tabular}




\section{Results of experiments}

ARGUS is designed to measure the strain and thickness reduction in sheet metal caused by stamping, to detect hot spots in the validation process of new and reworked stamping tools and to measure the formability of sheet metal in stamping applications.

As a result, the major (Fig. 7) and minor strain and the thickness reduction (Fig. 8) of the sheet metal are available as surface information.
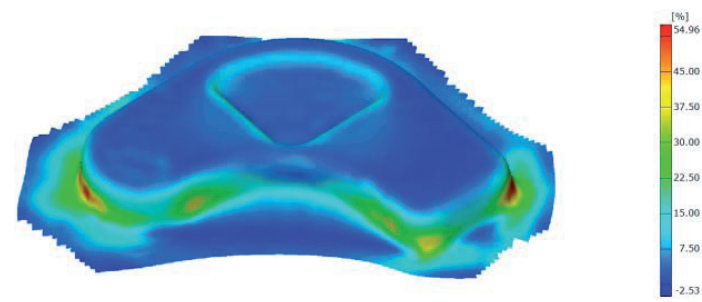

Fig. 7: Major strain distribution of stamped part.

The thickness reduction is directly calculated from the major and minor strain assuming a constant volume.
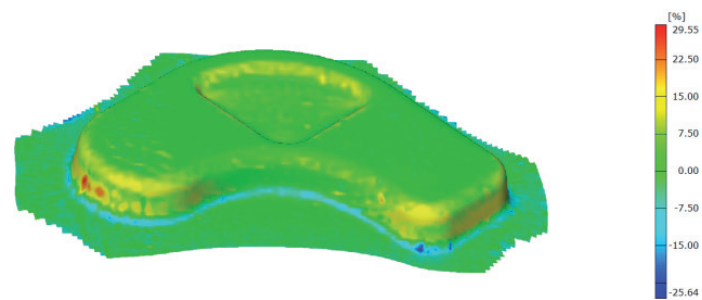

Fig. 8: Thickness reduction distribution of the part.

The forming limit diagram compares the major and minor strain with the material characteristics (Fig. 9). Thus, the forming process can directly be evaluated with respect to the material limits. $[9,10]$

The FLD shows clearly that a few measurement points are above the forming limit curve (Fig. 10) of the used material. In these areas the part will probably tear or is so weak that it cannot be used at all.

All results are calculated on the object's surface as they are determined directly from the dots. In areas of smaller radii or when measuring thick sheet metals, the results and particularly the thickness reduction are falsified. The software provides for calculating the results in the center plane of the sheet metal by the possibility to enter the thickness of the sheet metal and the viewing direction. As the surface of the object is known because of the 3D coordinates, the system intersects the normal vector of each dot with the center plane of the sheet metal. Thus, the surface point is projected onto the center plane and the deformation is calculated again on this basis. Fig. 11 shows that there are significant differences in thickness reduction when taking into account the thickness of the sheet metal.

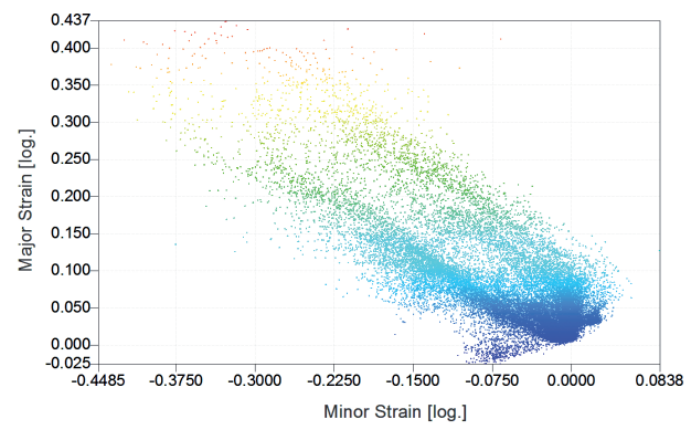

Fig. 9: Forming Limit Diagram.

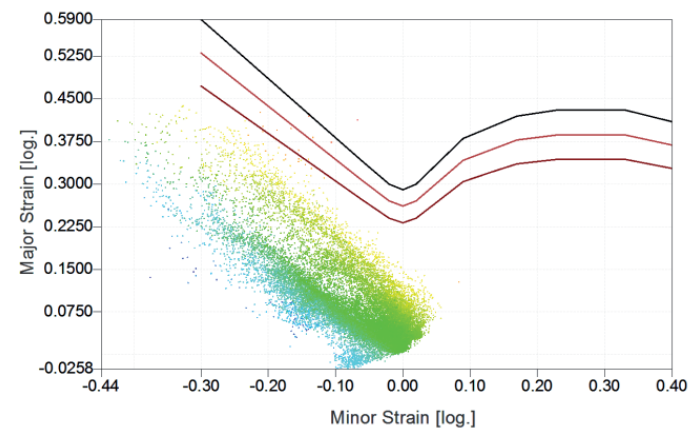

Fig. 10: Forming Limit Curve in FLD of formed material.
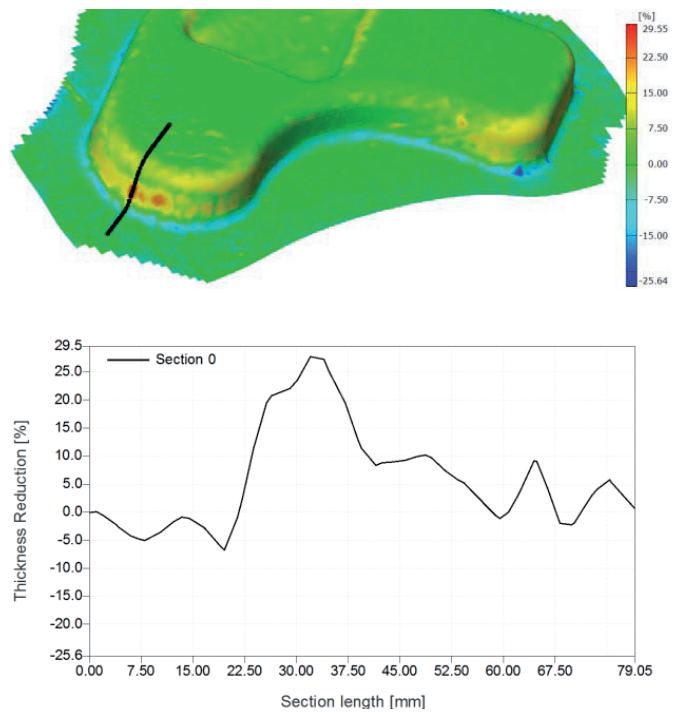

Fig. 11: Thickness reduction along a section on the surface of the sheet metal. 


\section{Conclusion}

Optical measuring systems for forming analysis and material property determination are a part of advanced process chains in the development of products and production processes for sheet metals and tools. Already today, time, costs and quality are optimized, thus increasing the competitiveness of companies. Nowadays, these measuring technologies are used increasingly for automated inspection tasks due to their further integration in processes and the availability of powerful data processing systems.

\section{Acknowledge}

This contribution is the result of the project implementation: Center for research of control of technical, environmental and human risks for permanent development of production and products in mechanical engineering (ITMS: 26220120060) supported by the R\&D Operational Programme funded by the ERDF.

\section{References}

[1] POLLÁK, L.: Anizotropia a hlbokotažnost' ocel'ových plechov. ALFA, Bratislava, 1978

[2] BLAŠČÍK, F. - POLÁK, K.: Teória tvárnenia. Alfa, bratislava, 1989

[3] MIELNIK, E. M.: Metalworking science and Engineering. Mc Graw - Hill, Inc., New York, 1991, ISBN 0-07-041904-3

[4] FOREJT, M. - PÍŠKA, M.: Teorie obrábění, tváření a nástroje. VUT Brno, 2006. - 225 s. ISBN 80-214-2374-9

[5] http://www.gom.com (26.10.2011)

[6] DAMOULIS, G. L., GOMES, E. and BATALHA, G. F.: New trends in sheet metal forming analysis and optimization trough the use of optical measurement technology to control springback. International Journal of Material Forming. Vol. 3, No. 1, pp. 29-39.

[7] SCHNEIDER, M., FRIEBE, H. and GALANULIS, K.: Validation and optimization of numerical simulations by optical measurements of tools and parts. In: IDDRG 2008 Int. Conf., Olofström, Sweden.

[8] EVIN, E.: Design of dual phase steel sheets for auto body. In: Acta Mechanica Slovaca, Vol.15, No.2 (2011), 42 - 48.

[9] FRACCZ,W., STACHOWICZ, F.: Determination of the forming limit diagram of zinc electro-galvanized steel sheets, Metallurgy, 51 (2012) 161-167.

[10] SLOTA, J. - SPIŠÁK, E.: Determination of forming -limit diagrams considering various models for steel sheets. In: Acta Mechanica Slovaca, Vol.15, No.1 (2011), 56 - 62. 